\title{
Prevalence and determinants of chronic kidney disease in community-dwelling elderly by various estimating equations
}

\author{
Dietrich Rothenbacher ${ }^{1 *}$, Jochen Klenk ${ }^{1}$, Michael Denkinger ${ }^{2}$, Mahir Karakas $^{3}$, Thorsten Nikolaus², \\ Richard Peter ${ }^{1}$ and Wolfgang Koenig ${ }^{3}$ for the ActiFE Study Group
}

\begin{abstract}
Background: Chronic kidney disease (CKD) represents a global public health problem. Few data exist in the elderly. The objective of the current study is to estimate the prevalence of CKD by means of various established and new equations and to identify the main determinants of CKD in elderly.

Methods: The ActiFE UIm (Activity and Function in the Elderly in Ulm) study is a population-based cohort study in people of 65 years and older. Kidney function was assessed by means of estimated glomerular filtration rate (eGFR) based on two creatinine- (Cr-; MDRD, CKD-EPI) and one cystatin C - (CysC-) based method. The relationship between various potential risk factors and CKD was quantified using unconditional logistic regression.

Results: A total of 1471 subjects were in the final analysis (mean age 75.6 years, SD 6.56). Overall, prevalence of CKD (eGFR $<60 \mathrm{~mL} / \mathrm{min} / 1.73 \mathrm{~m}^{2}$ ) was $34.3 \%$ by MDRD, 33.0\% by CKD-EPI, and $14.6 \%$ by the CysC-based eGFR. All eGFRs showed statistically significant correlations with C-reactive protein, uric acid, as well as with lipid values. In multivariable analysis age was clearly related to prevalence of CKD and the risks were highest with the CysC-based equation. Females had a higher risk for CKD stages 3-5 with MDRD (OR 1.63; 95\% Cl: 1.23-2.16) whereas the OR was $1.23(95 \% \mathrm{Cl} 0.92-1.65)$ with the CKD-Epi and $\mathrm{OR}=0.89$ (95\% Cl 0.58-1.34) with the CysC-based equation after multivariable adjustment. Although the cystatin C based definition of CKD resulted in a lower prevalence compared to the creatinine based ones, other measures of renal damage such as albuminuria were more prevalent in those defined by CysC-eGFR.

Conclusions: Prevalence of CKD is very variable based on the used estimating equation. More work is needed to evaluate the various estimating equations especially in elderly before we are able to assess the practical consequences of the observed differences.
\end{abstract}

Keywords: Elderly, Chronic kidney disease, Population-based study, Estimating equations, Risk factors

\section{Background}

Chronic kidney disease (CKD) represents a global public health problem and affects a large proportion of the adult population worldwide [1,2]. CKD has a complicated relationship with diabetes and hypertension and other associated diseases, and it is an independent risk factor for cardiovascular diseases (CVD) as well as for all cause mortality [1]. Outcomes of CKD include not

\footnotetext{
* Correspondence: dietrich.rothenbacher@uni-ulm.de

${ }^{1}$ Institute of Epidemiology and Medical Biometry, UIm University, Ulm,

Helmholtzstr 22, D-89081, Germany

Full list of author information is available at the end of the article
}

only progression to end-stage renal disease (ESRD) but also complications such as hypertension, malnutrition, anaemia, bone disease and a decreased quality of life $[3,4]$. CKD is also a proposed risk factor for adverse outcomes in other chronic diseases such as infections and various cancers.

In the meantime a paradigm shift has occurred. Early, subclinical CKD (and not only ESRD) has been associated with a large burden of disease and mortality [5]. This finding is clinically important, because early detection and treatment of CKD can prevent or delay the progression of CKD to ESRD and to other more common, 
but still severe complications related to CVD and to potential side effects or overdosing of medication.

Since the Kidney Disease Outcome Quality Initiation (K/DOQI) clinical practice guideline for definition and classification of CKD have been published and updated [5,6], more epidemiologic data about prevalence of CKD in the general population are available. However, few studies focused on risk factors for early stages of CKD among elderly and used the different suggested estimating equations of glomerular filtration rate (eGFR) to assess renal function in clinical practice.

The objective of the current study is to estimate the prevalence of CKD by means of $\mathrm{Cr}$ - and $\mathrm{CysC}$ - based estimating equations and to identify the main determinants of CKD in a large population-based group of noninstitutionalized elderly subjects.

\section{Methods}

\section{Ethics statement}

The study was approved by the ethical committee of Ulm University. All participants provided written informed consent.

\section{Study population}

The ActiFE Ulm (Activity and Function in the Elderly in Ulm) study is a population-based cohort study in subjects aged 65 years and older, located in Ulm and adjacent regions in Southern Germany. Based on data from the local registry office a random-sample of 7,624 noninstitutionalized inhabitants was contacted by mail and asked for participation. Exclusion criteria were severe deficits in cognition, vision or hearing that precluded the accomplishment of most assessments or serious German language difficulties. Between March 2009 and April 2010, 1,506 eligible individuals agreed to participate and underwent the baseline assessments (participation rate: 19.8\%). Further details are described elsewhere $[7,8]$.

\section{Data collection}

Participants satisfying the inclusion criteria were contacted by a field worker to make an individual appointment for an interview at home. Participants who did not want to be visited in their home were given the alternative to meet the interviewer in a designated room located at the Bethesda Geriatric Clinic, Ulm.

In total there were three visits incorporated in the ActiFE Ulm study, all to be completed within seven days. The first and last visits were conducted by a study nurse, the visit in between by a physician who conducted a physical exam. During the first visit the interviewer obtained informed consent from the participant, provided information about the study procedure and conducted the first half of the baseline interview. The second visit was conducted by a physician. In the last visit the interviewer accomplished the second half of the baseline interview. Briefly, the core questionnaires included questions on socio-demographic characteristics, diagnosis and related respiratory symptoms of asthma and COPD, physical functioning and activity, comorbidity ("has a doctor ever told you..."), exposures and potential risk factors related to asthma, COPD and physical activity, clinical management (treatment and self management issues), accessibility and use of health services.

If participants had separately agreed, blood was collected during the second visit. Participants who were successfully instructed on visit one, also provided midstream urine (morning void).

\section{Laboratory methods}

Blood at baseline was drawn in fasting state under standardized conditions. Serum creatinine $(\mathrm{Cr})$ was measured by the kinetic Jaffe method (inter-assay CV 1.2$3.0 \%)$ on a IMDS-traceable reference standard. Serum cystatin $\mathrm{C}(\mathrm{CysC})$ was measured by immunonephelometry on a Behring Nephelometer II (inter-assay CV 2.9$3.2 \%)$. C-reactive protein (CRP) was determined by a high-sensitivity assay on the same device (inter-assay $\mathrm{CV}$ 5.2-6.4\%). Urinary albumin was measured by immunonephelometry assay (inter-assay CV 2.8\%). Blood lipid measurements and other measurements were done by routine methods. All markers were measured in a blinded fashion.

\section{Assessment of chronic kidney disease}

Kidney function was assessed by means of eGFR based on the three estimating equations as described below:

Cr-eGFR according to the Simplified Modification of Diet in Renal Disease (MDRD) equation [9]: $\mathrm{Cr}-$ $\operatorname{eGFR}($ MDRD $)=175 \times(\mathrm{Cr})^{-1.154} \times(\text { age })^{-0.203} \times(0.742$ if female $) \times(1.21$ if African American $)$.

eGFRcrea according to the Chronic Kidney Disease Epidemiology Collaboration (CKD-EPI) equation [10]: $\mathrm{eGFR}=141 \times \min (\mathrm{Cr} / \mathrm{k}, 1)^{\mathrm{a}} \times \max (\mathrm{Cr} / \mathrm{k}, 1)-{ }^{1.209} \times$ $(0.993)^{\text {age }} \times(1.018$ if female $) \times(1.159$ if black $)$ where $\mathrm{k}$ is 0.7 for females and 0.9 for males, a is -0.329 for females and -0.411 for males, min indicates the minimum of $\mathrm{Cr} / \mathrm{k}$ or 1 , and max indicates the maximum of $\mathrm{Cr} / \mathrm{k}$ or 1 .

Cystatin C-based eGFR according to CKD-EPI collaboration $\quad[11,12]: \quad$ CysC - eGFR $($ CKD - EPI $)=127.7 \times$ $(\mathrm{CysC})^{-1.17} \times$ age $^{-0.13} \times(0.91$ if female $) \times(1.06$ if black $)$.

CKD stage $3-5$ was defined as eGFR of less than $60 \mathrm{~mL} / \mathrm{min} / 1.73 \mathrm{~m}^{2}$ [13]. In equations, $\mathrm{Cr}$ is given in $\mathrm{mg} / \mathrm{dL}, \mathrm{CysC}$ in $\mathrm{mg} / \mathrm{L}$, age in years, weight in $\mathrm{kg}$, and eGFR in $\mathrm{mL} / \mathrm{min} / 1.73 \mathrm{~m}^{2}$. 
Renal damage was defined as albumin-to-creatinine ratio (ACR) in spot urine sample (microalbuminuria ACR 30 to $<300 \mathrm{mg} / \mathrm{g}$, macroalbuminuria $\geq 300 \mathrm{mg} / \mathrm{g}$ ).

\section{Statistical analysis}

Descriptive statistics were calculated to describe the main characteristics of the study population. In addition prevalence of CKD was calculated according to the various eGFR estimating equations, stratified by age and gender. Correlations between various renal function markers, eGFR and biochemical markers were calculated by the non-parametric partial correlation coefficient after adjustment for age and gender. The relationship between various potential risk factors and CKD was quantified using unconditional logistic regression. Mainly factors which were described as potential risk factors in the literature were considered. Odds ratios (OR) and 95\% confidence intervals (CI) were estimated in crude and adjusted analyses. All analyses were performed using SAS 9.2.

\section{Results}

Overall 1471 subjects aged 65 and older with complete data on creatinine, cystatin $C$ and albumin were included in the final analysis (mean age 75.6 years, SD 6.56) (Table 1). More males were included than females (56.8\% versus $43.2 \%)$. Most of the subjects were married (65.5\%) and had a school education of 9 years or less $(58.6 \%)$. The mean body mass index was $27.6 \mathrm{~kg} / \mathrm{m}^{2}$ and $24.2 \%$ were obese. More than half had a history of hypertension, $8.6 \%$ had myocardial infarction, $14.5 \%$ a history of heart failure, and $13.3 \%$ reported a physician-diagnosed history of diabetes. Only $2.9 \%$ reported a history of CKD.

The mean (SD) of eGFR was 65.2 (14.6), 65.5 (14.9), and $81.7(21.8) \mathrm{mL} / \mathrm{min} / 1.73 \mathrm{~m}^{2}$ respectively, based on

Table 1 Characteristics of study population $(n=1471)$

\begin{tabular}{|c|c|c|}
\hline Age, mean (SD) & years & $75.6(6.56)$ \\
\hline \multirow[t]{3}{*}{$\bar{n}(\%)$} & $65-69$ & $351(23.9)$ \\
\hline & $70-79$ & $673(45.8)$ \\
\hline & $\geq 80$ & $447(30.4)$ \\
\hline \multirow[t]{2}{*}{ Gender, n (\%) } & male & $836(56.8)$ \\
\hline & female & $635(43.2)$ \\
\hline \multirow[t]{2}{*}{ Family status, n (\%) } & married & $960(65.5)$ \\
\hline & widowed & $362(24.7)$ \\
\hline Duration of school education, & $\leq 9 \mathrm{yrs}$ & $849(58.6)$ \\
\hline \multirow[t]{2}{*}{$n(\%)$} & $10-11 \mathrm{yrs}$ & $334(23.1)$ \\
\hline & $\geq 12$ yrs & $266(18.4)$ \\
\hline \multirow[t]{4}{*}{ Alcohol consumption, n (\%) } & daily & $448(31.0)$ \\
\hline & several time per week or month & $741(51.3)$ \\
\hline & $<1$ time per month & $243(16.8)$ \\
\hline & never & $12(0.8)$ \\
\hline \multirow[t]{3}{*}{ Smoking status, n (\%) } & smoker & $136(9.3)$ \\
\hline & former smoker & $601(41.0)$ \\
\hline & never-smoker & $729(49.7)$ \\
\hline \multirow[t]{2}{*}{ Body Mass Index, mean (SD) } & $\mathrm{kg} / \mathrm{m}^{2}$ & $27.6(4.16)$ \\
\hline & $\geq 30 \mathrm{~kg} / \mathrm{m}^{2}, \mathrm{n}(\%)$ & $356(24.2)$ \\
\hline \multirow[t]{5}{*}{ History of co-morbidity n (\%) } & hypertension & $784(53.3)$ \\
\hline & myocardial infarct & $127(8.6)$ \\
\hline & heart failure & $213(14.5)$ \\
\hline & chronic kidney disease & $43(2.9)$ \\
\hline & diabetes & $197(13.4)$ \\
\hline Creatinine $^{a}$ & $\mathrm{mg} / \mathrm{dL}$ & $0.98(0.87 ; 1.14)$ \\
\hline Cystatin $C^{a}$ & $\mathrm{mg} / \mathrm{L}$ & $0.88(0.77 ; 1.03)$ \\
\hline C-reactive protein ${ }^{a}$ & $\mathrm{mg} / \mathrm{L}$ & $1.70(0.89 ; 3.70)$ \\
\hline
\end{tabular}

${ }^{\bar{a}}$ median (interquartile range, Q1, Q3). 
MDRD, CKD-EPI and CysC estimating equation. Figure 1 shows the distribution of eGFR in a box plot according to males and females and in the various age categories. In general, values were much higher when the $\mathrm{CysC}$ based equations were applied.

Table 2 shows the prevalence of the various stages of CKD. By means of the MDRD, the CKD-EPI, and the CysC-based eGFR, 61.2\%, 62.5\%, and 79.3\%, respectively, had no kidney damage with normal or mildly decreased eGFR. Notably, especially among women these numbers were especially different ((MDRD, 58.0\%, CKD-EPI 62.4\%, CysC-based CKD 82.2\%).

Table 3 shows the prevalence of CKD by means of different estimating equations. Overall, prevalence of CKD stage $3-5$ was $34.3 \%$ by MDRD, $33.0 \%$ by CKD-EPI, and $14.6 \%$ by the CysC based estimating equations. 9.9\% had a microor macroalbuminuria. On the basis of the creatinine-based eGFRs women had a higher prevalence compared to men, this was most pronounced with the MDRD; the highest prevalence was reached in the oldest age categories, reaching $61.4 \%$ in women aged 80 and over based on the CKDEPI eGFR. In contrast, the CysC based eGFR showed a higher prevalence in men when compared to women and the increase with age was less steep, reaching a maximum of $32.3 \%$ in the category women aged 80 and over.
Table 4 shows the age and gender adjusted partial correlation of the various renal function markers and eGFRs with various biochemical markers. The correlation between $\mathrm{Cr}$ and $\mathrm{CysC}$ was 0.61 ( $\mathrm{p}<0.001)$. The correlation of $\mathrm{Cr}$ and $\mathrm{Cys} C$ with albumin in the urine was 0.08 $(\mathrm{p}=<0.001)$ and $0.13(\mathrm{p}<0.001)$, respectively. Both Crbased eGFRs showed no correlation with ACR, whereas the CysC based eGFR did $(\mathrm{r}=-0.07, \mathrm{p}=<0.001)$. All eGFRs showed statistically significant correlations with markers of inflammation (CRP, WBC), uric acid, as well as with lipid values. Age- and gender adjusted associations of $\mathrm{Cr}$, CysC with haemoglobin were negative and with MDRD, CKD-Epi and CysC-based eGFR positive, indicating that higher eGFR levels were associated with higher haemoglobin.

Table 5 shows the prevalence of albuminuria, an established renal damage marker, with CKD based on the different estimating equations in the subset of elderly. The proportions of micro- and marcoalbuminuria were quite similar among MDRD and CKD-Epi, they were higher among the CysC based eGFR.

Table 6 presents the association of various sociodemographic and medical characteristics with prevalence of CKD stage 3-5. Age was clearly related to prevalence of $\mathrm{CKD}$ and risks were highest in the CysC-based equation.

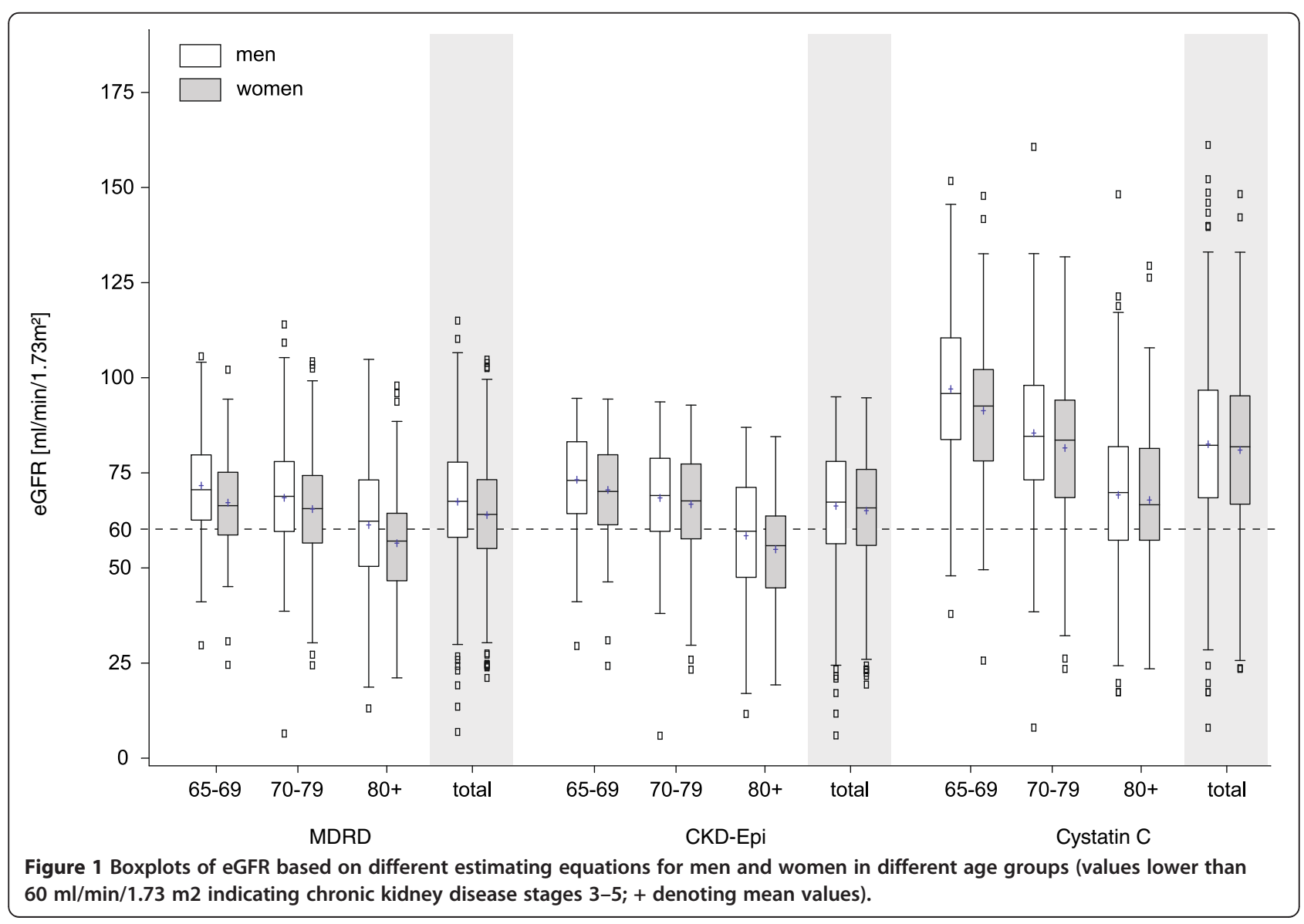


Table 2 Prevalence of stages of chronic kidney disease according to the various estimating equations

\begin{tabular}{|c|c|c|c|c|c|c|}
\hline Marker & $\begin{array}{c}\text { Stage of } \\
\text { CKD }\end{array}$ & Description & eGFR $^{a}$ & $\begin{array}{l}\text { Men } \\
\text { N (\%) }\end{array}$ & $\begin{array}{c}\text { Women } \\
\text { N (\%) }\end{array}$ & $\begin{array}{l}\text { Total } \\
\text { N (\%) }\end{array}$ \\
\hline \multirow[t]{5}{*}{ MDRD } & - & No kidney damage with normal or mildly decreased eGFR & $\geq 60$ & $532(63.6)$ & $368(58.0)$ & $900(61.2)$ \\
\hline & 1 & Kidney damage with normal eGFR & $\geq 90$ & $3(0.4)$ & $1(0.2)$ & $4(0.3)$ \\
\hline & 2 & Kidney damage with mildly decreased eGFR & $60-89$ & $46(5.5)$ & $17(2.7)$ & $63(4.3)$ \\
\hline & 3 & Moderately decreased eGFR & $30-59$ & $245(29.3)$ & $239(37.6)$ & $484(32.9)$ \\
\hline & $4 / 5$ & Severely decreased eGFR, kidney failure & $<30$ & $10(1.2)$ & $10(1.6)$ & $20(1.4)$ \\
\hline \multirow[t]{5}{*}{ CKD-EPI } & - & No kidney damage with normal or mildly decreased eGFR & $\geq 60$ & $523(62.6)$ & $396(62.4)$ & $919(62.5)$ \\
\hline & 1 & Kidney damage with normal eGFR & $\geq 90$ & $2(0.2)$ & $1(0.2)$ & $3(0.2)$ \\
\hline & 2 & Kidney damage with mildly decreased eGFR & $60-89$ & $46(5.5)$ & $17(2.7)$ & $63(4.3)$ \\
\hline & 3 & Moderately decreased eGFR & $30-59$ & $253(30.3)$ & 209 (32.9) & $462(31.4)$ \\
\hline & $4 / 5$ & Severely decreased eGFR, kidney failure & $<30$ & $12(1.4)$ & $12(1.9)$ & $24(1.6)$ \\
\hline \multirow[t]{5}{*}{ Cystatin-C based eGFR } & - & No kidney damage with normal or mildly decreased eGFR & $\geq 60$ & $645(77.2)$ & $522(82.2)$ & $1167(79.3)$ \\
\hline & 1 & Kidney damage with normal eGFR & $\geq 90$ & $18(2.2)$ & $4(0.6)$ & $22(1.5)$ \\
\hline & 2 & Kidney damage with mildly decreased eGFR & $60-89$ & $53(6.3)$ & $15(2.4)$ & $68(4.6)$ \\
\hline & 3 & Moderately decreased eGFR & $30-59$ & $113(13.5)$ & $89(14.0)$ & $202(13.7)$ \\
\hline & $4 / 5$ & Severely decreased eGFR, kidney failure & $<30$ & $7(0.8)$ & $5(0.8)$ & $12(0.8)$ \\
\hline
\end{tabular}

Females had a higher risk for CKD stage 3-5 with MDRD (OR 1.63; 95\% CI: 1.23-2.16) whereas the OR was $1.23(95 \%$ CI $0.92-1.65)$ with the CKD-Epi and $\mathrm{OR}=0.89$ (95\% CI 0.58-1.34) with the CysC-based equation after multivariable adjustment.
Alcohol consumption showed also a negative association with prevalence of CKD and remained statistically significant after full adjustment for all estimating equations. Furthermore, similar associations were seen with manifest obesity, partly hypertension and subjects with a history of

Table 3 Prevalence of chronic kidney disease stages 3-5 (eGFR $<60 \mathrm{~mL} / \mathrm{min}$ per $1.73 \mathrm{~m}^{2}$ ) in various age groups and according to gender based on different estimating equations

\begin{tabular}{|c|c|c|c|c|}
\hline Marker & Age group & $\begin{array}{l}\text { Men } \\
\text { N (\%) }\end{array}$ & $\begin{array}{c}\text { Women } \\
\text { N (\%) }\end{array}$ & $\begin{array}{l}\text { Total } \\
\text { N (\%) }\end{array}$ \\
\hline \multirow[t]{4}{*}{ MDRD } & $65-69$ & $26(14.5)$ & $50(29.1)$ & $76(21.7)$ \\
\hline & $70-79$ & $101(27.5)$ & $105(34.4)$ & 206 (30.6) \\
\hline & $80+$ & $128(44.3)$ & $94(59.5)$ & $222(49.7)$ \\
\hline & Overall & $255(30.5)$ & $249(39.2)$ & $504(34.3)$ \\
\hline \multirow[t]{4}{*}{ CKD-EPI } & $65-69$ & $21(11.7)$ & $34(19.8)$ & $55(15.7)$ \\
\hline & $70-79$ & $98(26.6)$ & $90(29.5)$ & $188(27.9)$ \\
\hline & $80+$ & $146(50.5)$ & $97(61.4)$ & $243(54.4)$ \\
\hline & Overall & $265(31.7)$ & $221(34.8)$ & $486(33.0)$ \\
\hline \multirow[t]{4}{*}{ Cystatin-C based eGFR } & $65-69$ & $4(2.2)$ & $7(4.1)$ & $11(3.1)$ \\
\hline & $70-79$ & $30(8.2)$ & $36(11.8)$ & $66(9.8)$ \\
\hline & $80+$ & $86(29.8)$ & $51(32.3)$ & $137(30.7)$ \\
\hline & Overall & $120(14.4)$ & $94(14.8)$ & $214(14.6)$ \\
\hline \multirow[t]{4}{*}{ Albumin creatinine ratio $(A C R)>30 \mathrm{mg} / \mathrm{g}$} & $65-69$ & $17(9.5)$ & $7(4.1)$ & $24(6.8)$ \\
\hline & $70-79$ & $43(11.7)$ & $12(3.9)$ & $55(8.2)$ \\
\hline & $80+$ & 49 (17.0) & 17 (10.8) & $66(14.8)$ \\
\hline & Overall & 109 (13.0) & $36(5.7)$ & $145(9.9)$ \\
\hline
\end{tabular}


Table 4 Association of different renal function parameters and estimation equations with biochemical markers after adjustment for age and gender (spearman partial correlation coefficient and p-value)

\begin{tabular}{|c|c|c|c|c|c|c|c|c|c|c|c|c|}
\hline & $\begin{array}{c}\text { CysC } \\
\text { (mg/L) }\end{array}$ & $\begin{array}{l}\text { MDRD } \\
\text { eGFR }\end{array}$ & $\begin{array}{c}\text { CKD-EPI } \\
\text { eGFR }\end{array}$ & $\begin{array}{l}\text { CysC- } \\
\text { eGFR }\end{array}$ & ACR & $\begin{array}{c}\text { CRP } \\
\text { (mg/L) }\end{array}$ & $\begin{array}{l}\text { Uric acid } \\
(\mu \mathrm{mol} / \mathrm{L})\end{array}$ & $\begin{array}{c}\text { Cholesterol } \\
(\mathrm{mmol} / \mathrm{L})\end{array}$ & $\begin{array}{c}\mathrm{HDL} \\
(\mathrm{mmol} / \mathrm{L})\end{array}$ & $\begin{array}{c}\mathrm{LDL} \\
(\mathrm{mmol} / \mathrm{L})\end{array}$ & $\begin{array}{c}\text { WBC } \\
\text { (Giga/L) }\end{array}$ & $\begin{array}{l}\text { Hemoglobin } \\
(\mathrm{g} / \mathrm{dL})\end{array}$ \\
\hline \multirow[t]{2}{*}{ Creatinine $(\mathrm{mg} / \mathrm{dL})$} & 0.61 & -0.96 & -0.96 & -0.60 & -0.00 & 0.13 & 0.44 & -0.07 & -0.18 & -0.06 & 0.07 & -0.05 \\
\hline & $<0.001$ & $<0.001$ & $<0.001$ & $<0.001$ & 0.89 & $<0.001$ & $<0.001$ & 0.005 & $<0.001$ & 0.03 & 0.007 & 0.08 \\
\hline \multirow[t]{2}{*}{ CysC (mg/L) } & & -0.60 & -0.60 & -1.00 & 0.07 & 0.24 & 0.39 & -0.10 & -0.24 & -0.05 & 0.10 & -0.08 \\
\hline & & $<0.001$ & $<0.001$ & $<0.001$ & 0.006 & $<0.001$ & $<0.001$ & $<0.001$ & $<0.001$ & 0.04 & $<0.001$ & 0.003 \\
\hline \multirow[t]{2}{*}{ MDRD eGFR } & & & 1.00 & 0.60 & 0.00 & -0.14 & -0.41 & 0.07 & 0.16 & 0.06 & -0.06 & 0.05 \\
\hline & & & $<0.001$ & $<0.001$ & 0.91 & $<0.001$ & $<0.001$ & 0.011 & $<0.001$ & 0.03 & 0.02 & 0.04 \\
\hline \multirow[t]{2}{*}{ CKD-Epi eGFR } & & & & 0.60 & 0.02 & -0.13 & -0.41 & 0.07 & 0.16 & 0.06 & -0.06 & 0.05 \\
\hline & & & & $<0.001$ & 0.95 & $<0.001$ & $<0.001$ & 0.01 & $<0.001$ & 0.03 & 0.02 & 0.04 \\
\hline \multirow{2}{*}{$\begin{array}{l}\text { Cystatin-C } \\
\text { based eGFR }\end{array}$} & & & & & -0.07 & -0.25 & -0.38 & 0.09 & 0.24 & 0.05 & -0.10 & 0.08 \\
\hline & & & & & 0.005 & $<0.001$ & $<0.001$ & $<0.001$ & $<0.001$ & 0.04 & $<0.001$ & 0.001 \\
\hline \multirow[t]{2}{*}{ ACR (urine) } & & & & & & 0.10 & 0.03 & -0.04 & -0.03 & -0.05 & 0.06 & -0.07 \\
\hline & & & & & & $<0.001$ & 0.23 & 0.14 & 0.27 & 0.08 & 0.03 & 0.01 \\
\hline
\end{tabular}

Abbreviations: $A C R=$ Albumine-creatinine ratio $(\mathrm{mg} / \mathrm{g})$, CysC = cystatine $C, M D R D=$ Modification of Diet in Renal Disease Study, eGFR = estimated glomerular filtration rate.

$\left(\mathrm{mL} / \mathrm{min} / 1.73 \mathrm{~m}^{2}\right), \mathrm{CKD}-\mathrm{Ep} \mathrm{=}=$ Chronic Kidney Disease Epidemiology Collaboration, $\mathrm{CRP}=\mathrm{C}$-reactive protein, HDL = high-density lipoprotein, LDL = low density lipoprotein, $\mathrm{WBC}=$ white blood cell count.

myocardial infarction with all three estimating equations, and with heart failure with the CysC-based CKD definition.

\section{Discussion}

In this large population based study involving 1471 subjects aged 65 to 91 years and randomly selected from the general population in the area of Ulm (Germany) prevalence of chronic kidney disease stage 3-5 varied considerably between $14.6 \%$ on a CysC-based estimating equation to $33.0 \%$ and $34.3 \%$ based on CKD-EPI and MDRD estimating equation, respectively. A steep increase with age was found with all three equations. Although the cystatin $\mathrm{C}$ based definition of CKD resulted in a lower prevalence compared to the creatinine based ones, other measures of renal damage such as albuminuria were more prevalent in those defined by $\mathrm{CysC}$ eGFR. The association of gender with CKD was quite different, depending on the definition used: women had a higher risk for CKD with the MDRD.
The prevalence of CKD in our elderly population is roughly in line with data from others studies when considering the Cr-based estimating equations [2]. In a different population based study in subjects aged 5075 years also conducted in Germany and using the MDRD, however, the prevalence was slightly higher in comparable age strata [14]. Prevalence of CKD in the Three-City study including 8705 community-dwelling elderly aged 65 years or older was $13.7 \%$ and $12.9 \%$ with the MDRD and CKD-EPI equation, and the long-term risk estimates were quite similar with both equations [15]. In a study from the US conducted in octogenarians (mean age 86 years) in which beside CKD-EPI and also two cystatin $C$ based equations were used to define CKD, the patterns were quite similar to our results [16]. In this study of Shastri et al. the CKD-EPI resulted in prevalence of $51.3 \%$ and with the one-variable CysCbased equation in a prevalence of $33.0 \%$. In our study, in the respective age category of $80+$ years the CKD-EPI lead to a prevalence of $54.4 \%$ and the CysC-based

Table 5 Prevalence of micro- and macroalbuminuria in subjects with and without chronic kidney disease stages 3-5 (eGFR $<60 \mathrm{~mL} / \mathrm{min}$ per $1.73 \mathrm{~m}^{2}$ ) based on different estimating equations

\begin{tabular}{|c|c|c|c|c|c|c|}
\hline & \multicolumn{6}{|c|}{ Chronic kidney disease $\left(\left(\mathrm{eGFR}<60 \mathrm{~mL} / \mathrm{min}\right.\right.$ per $\left.1.73 \mathrm{~m}^{2}\right)$} \\
\hline & \multicolumn{2}{|c|}{ MDRD GFR } & \multicolumn{2}{|c|}{ CKD-Epi } & \multicolumn{2}{|c|}{ CsyC-based } \\
\hline & no & yes & no & yes & no & yes \\
\hline Normal, N (\%) & $900(93.1)$ & $426(84.5)$ & 919 (93.3) & $407(83.7)$ & $1167(92.8)$ & $159(74.3)$ \\
\hline Microalbuminuria, N (\%) & $60(6.2)$ & $65(12.9)$ & $59(6.0)$ & $66(13.6)$ & $79(6.3)$ & $46(21.5)$ \\
\hline Macroalbuminuria, N (\%) & $7(0.7)$ & $13(2.6)$ & $7(0.7)$ & $13(2.7)$ & $11(0.9)$ & $9(4.2)$ \\
\hline Total, N (\%) & $967(100.0)$ & $504(100.0)$ & $985(100.0)$ & $486(100.0)$ & $1257(100.0)$ & $214(100.0$ \\
\hline
\end{tabular}

Microalbuminuria ACR 30 to $<300 \mathrm{mg} / \mathrm{g}$, macroalbuminuria $A C R \geq 300 \mathrm{mg} / \mathrm{g}$. 
Table 6 Association of various factors with chronic kidney disease (eGFR $<60 \mathrm{~mL} / \mathrm{min} / 1.73 \mathrm{~m}^{2}$ ) based on different estimating equations

\begin{tabular}{|c|c|c|c|c|c|c|c|}
\hline & \multicolumn{2}{|c|}{ MDRD GFR } & \multicolumn{2}{|c|}{ CKD-Epi } & \multicolumn{2}{|c|}{ CsyC-based CKD } \\
\hline & & crude & adjusted $^{a}$ & crude & adjusted $^{a}$ & crude & adjusted $^{a}$ \\
\hline \multirow[t]{3}{*}{ Age } & $65-69$ & 1.00 (referent) & $1.00^{\text {(referent) }}$ & $1.00^{\text {(referent) }}$ & $1.00^{\text {(referent) }}$ & $1.00^{\text {(referent) }}$ & $1.00^{\text {(referent) }}$ \\
\hline & $70-79$ & $1.60(1.18 ; 2.16)$ & $1.52(1.11 ; 2.10)$ & $2.09(1.49 ; 2.91)$ & $1.98(1.40 ; 2.81)$ & $3.36(1.75 ; 6.45)$ & $3.30(1.64 ; 6.67)$ \\
\hline & $\geq 80$ & $3.57(2.61 ; 4.89)$ & $3.33(2.37 ; 4.74)$ & $6.41(4.55 ; 9.03)$ & $6.01(4.14 ; 8.73)$ & $13.66(7.25 ; 25.73)$ & $13.94(6.95 ; 27.98)$ \\
\hline Gender & female & $1.47(1.18 ; 1.83)$ & $1.63(1.23 ; 2.16)$ & $1.15(0.92 ; 1.43)$ & $1.23(0.92 ; 1.65)$ & $1.04(0.77 ; 1.39)$ & $0.89(0.58 ; 1.34)$ \\
\hline \multirow[t]{3}{*}{ Family status } & Married & $1.00^{\text {(referent) }}$ & $1.00^{\text {(referent) }}$ & $1.00^{\text {(referent) }}$ & $1.00^{\text {(referent) }}$ & $1.00^{\text {(referent) }}$ & $1.00^{\text {(referent) }}$ \\
\hline & widowed & $1.94(1.51 ; 2.49)$ & $1.24(0.93 ; 1.65)$ & $2.09(1.63 ; 2.69)$ & $1.29(0.96 ; 1.74)$ & $2.11(1.54 ; 2.90)$ & $1.17(0.79 ; 1.74)$ \\
\hline & other & $1.29(0.89 ; 1.86)$ & $1.12(0.75 ; 1.67)$ & $1.40(0.97 ; 2.03)$ & $1.33(0.88 ; 2.00)$ & $1.29(0.78 ; 2.14)$ & $1.34(0.75 ; 2.38)$ \\
\hline Duration of & $\leq 9 \mathrm{yrs}$ & $1.00^{\text {(referent) }}$ & $1.00^{\text {(referent) }}$ & $1.00^{\text {(referent) }}$ & $1.00^{\text {(referent) }}$ & $1.00^{\text {(referent) }}$ & $1.00^{\text {(referent) }}$ \\
\hline \multirow[t]{2}{*}{ school education } & $10-11$ yrs & $1.01(0.77 ; 1.31)$ & $1.11(0.83 ; 1.47)$ & $1.00(0.76 ; 1.31)$ & $1.13(0.84 ; 1.52)$ & $1.02(0.72 ; 1.46)$ & $1.17(0.78 ; 1.75)$ \\
\hline & $\geq 12$ yrs & $0.96(0.72 ; 1.29)$ & $1.18(0.86 ; 1.63)$ & $0.93(0.69 ; 1.25)$ & $1.11(0.80 ; 1.54)$ & $0.72(0.47 ; 1.10)$ & $0.85(0.53 ; 1.37)$ \\
\hline \multirow[t]{4}{*}{ Alcohol consumption } & daily & $0.49(0.36 ; 0.68)$ & $0.69(0.48 ; 1.01)$ & $0.54(0.39 ; 0.75)$ & $0.66(0.45 ; 0.97)$ & $0.43(0.29 ; 0.64)$ & $0.40(0.24 ; 0.66)$ \\
\hline & $\begin{array}{l}\text { several time per week } \\
\text { or per month }\end{array}$ & $0.54(0.40 ; 0.72)$ & $0.72(0.52 ; 1.00)$ & $0.55(0.41 ; 0.74)$ & $0.70(0.50 ; 0.98)$ & $0.37(0.26 ; 0.54)$ & $0.39(0.25 ; 0.60)$ \\
\hline & $<1$ time per month & $1.00^{\text {(referent) }}$ & $1.00^{\text {(referent) }}$ & $1.00^{\text {(referent) }}$ & $1.00^{\text {(referent) }}$ & $1.00^{\text {(referent) }}$ & $1.00^{\text {(referent) }}$ \\
\hline & never & $0.81(0.25 ; 2.62)$ & $0.57(0.17 ; 1.95)$ & $1.25(0.39 ; 3.99)$ & $0.93(0.28 ; 3.14)$ & $0.97(0.26 ; 3.71)$ & $0.68(0.16 ; 2.91)$ \\
\hline \multirow[t]{3}{*}{ Smoking status } & smoker & $0.56(0.37 ; 0.86)$ & $0.73(0.46 ; 1.16)$ & $0.61(0.40 ; 0.94)$ & $0.77(0.48 ; 1.24)$ & $0.85(0.50 ; 1.45)$ & $1.11(0.58 ; 2.12)$ \\
\hline & former smoker & $0.91(0.73 ; 1.14)$ & $1.04(0.79 ; 1.35)$ & $0.96(0.77 ; 1.21)$ & $0.99(0.75 ; 1.31)$ & $0.89(0.66 ; 1.21)$ & $0.83(0.56 ; 1.22)$ \\
\hline & never-smoker & $1.00^{\text {(referent) }}$ & $1.00^{\text {(referent) }}$ & $1.00^{\text {(referent) }}$ & $1.00^{\text {(referent) }}$ & $1.00^{\text {(referent) }}$ & $1.00^{\text {(referent) }}$ \\
\hline Body Mass Index & $\geq 30 \mathrm{~kg} / \mathrm{m}^{2}, \mathrm{n}(\%)$ & $1.57(1.22 ; 2.00)$ & $1.48(1.13 ; 1.94)$ & $1.51(1.18 ; 1.93)$ & $1.52(1.15 ; 2.01)$ & $1.87(1.37 ; 2.56)$ & $1.98(1.37 ; 2.85)$ \\
\hline \multirow[t]{4}{*}{ History of Co-morbidity, } & hypertension & $1.60(1.29 ; 1.99)$ & $1.28(1.00 ; 1.63)$ & $1.59(1.27 ; 1.98)$ & $1.23(0.96 ; 1.59)$ & $2.08(1.53 ; 2.84)$ & $1.54(1.07 ; 2.21)$ \\
\hline & myocardial infarct & $2.40(1.66 ; 3.46)$ & $2.18(1.45 ; 3.26)$ & $2.84(1.96 ; 4.10)$ & $2.40(1.59 ; 3.62)$ & $3.23(2.15 ; 4.84)$ & $2.22(1.39 ; 3.56)$ \\
\hline & heart failure & $1.49(1.11 ; 2.01)$ & $1.12(0.80 ; 1.55)$ & $1.45(1.08 ; 1.96)$ & $1.03(0.74 ; 1.45)$ & $2.41(1.70 ; 3.41)$ & $1.90(1.27 ; 2.84)$ \\
\hline & diabetes & $1.59(1.17 ; 2.15)$ & $1.37(0.98 ; 1.92)$ & $1.43(1.09 ; 1.94)$ & $1.14(0.80 ; 1.62)$ & $1.67(1.14 ; 2.44)$ & $1.14(0.74 ; 1.77)$ \\
\hline
\end{tabular}

${ }^{a}$ Multivariate logistic regression model and $95 \%$ confidence interval $(95 \% \mathrm{Cl}$ ) adjusted for gender, age, family status, duration of school education, alcohol consumption, smoking status, adipositas and history of co-morbidity (hypertension, myocardial infarction, heart failure, diabetes).

equation to $30.7 \%$. In a study from the US conducted in elderly patients aged 65 years and over the prevalence of CKD based on the MDRD was 44\% [17].

Notably we found a higher prevalence of CKD in women when using the MDRD estimating equation. It is consistent with results from a study conducted in a population of elderly from another State in Germany [14] and has been a consistent feature in a systematic review [2]. Beside gender differences in physiological factors the lower prevalence may also be a function of the correction factor for females in the $\mathrm{Cr}$-based equations. Men are de facto also at higher risk for ESRD compared to women, which is also indirect evidence for a higher burden of the underlying CKD, which finally may progress to ESRD [18].

In addition it is known that especially the MDRDbased eGFR overestimates renal function in general in elderly subjects [19] and part of the high prevalence may be accountable to it. In a population of volunteers (mean age 61.3 years, SD 8.6) MDRD underestimated eGFR in a healthy population compared to CysC-based ones [20]. Cr-based eGFR may show a large intra- and interindividual variation due to the dependence of $\mathrm{Cr}$ concentration on many factors such as muscle mass, dietary intakes and other diseases [2]. Recently the CKD-EPI formulation had been proposed to work better in the context of epidemiological studies [10]. CKD-EPI seems to misclassify fewer low-risk patients compared to MDRD [21]. Another study reported that compared to MDRD the CKD-EPI leads to higher estimates in young people and to lower estimates in elderly. The authors suggested an age dependent threshold for CKD [22].

We found a stronger association of established risk factors, comorbid conditions, and biochemical markers related more or less to risk for kidney disease with CysC-based definition of CKD. The only exception was uric acid which was stronger for $\mathrm{Cr}$-based eGFR. The association of metabolic risk factors such as HDL and insulin resistance (although the latter was not available in our study) had been described with early impairment 
of renal function, irrespective of markers of renal damage [23].

Several studies consistently found a better prognostic value of cystatin $\mathrm{C}$ or $\mathrm{Cys} C$-based estimating equations with all-cause mortality [24,25], CVD [26], and ESRD $[24,27]$. Adding CysC- to Cr-based measures to improve predictive accuracy was also suggested by some authors [24], however, this approach was not superior in other studies [26]. A meta-analysis also concluded that the diagnostic accuracy for measuring renal function is in favour for $\mathrm{CysC}$ when compared to $\mathrm{Cr}$. However, the study included a very heterogeneous patient population and only few elderly [28].

Currently there is a hot debate about the definition of CKD in elderly based on a fixed threshold $[29,30]$. The argument is that screening will identify many false positives, especially among elderly women, most of them having no evidence of kidney disease. The decrease in kidney function might be due to changes in kidney structure associated with aging [31] and be considered physiological. However, in a collaborative meta-analysis including more than 100,000 subjects from 14 studies the shape between eGFR and risk of all cause- and CVD-mortality was similar in age groups below and above age 65 years and the test for interaction between eGFR and age were not significant in most studies [1].

Although we found a strong association of CKD stage 3-5 with various cardiovascular diseases and risk factors, we found a statistically significant association with history of diabetes only in bivariate analyses, consistently for all three estimating equations. The lack of statistically significant associations with diabetes has also been reported by other investigators $[14,22]$.

When looking on the results the following limitations should be considered. We did not have GFR measurement, so we cannot determine the extent to which either $\mathrm{Cys} \mathrm{C}$ or $\mathrm{Cr}$ reflects the glomerular filtration rate as determined by a gold standard (i.e. inulin clearance). However, it is very difficult to obtain true GFR measurements in such a large population. Also, we only used a cross-sectional design, so the temporal association between the described risk factors and CKD cannot be assessed. Furthermore, we only had a single measurement of CKD, whereas usually for definition of CKD two measures within a time period of 3 months should be employed. The latter, however, is a limitation present in most of the cited epidemiological studies, but may indeed cause an increase in prevalence numbers. In addition, we used only one among the many suggested CysC-eGFR equations. Current available data on CysCeGFR equations are still very limited. Results from this study does not exclude the possibility that CysC-based eGFR overestimates GFR in the elderly. In this case, wide use of this equation may expose this population to drug overdosing and adverse effects. However, it is notably, that the proportion with no signs of renal damage is highest in the group with no CKD based on the CysCCKD definition. Therefore, further studies should evaluate the CysC-eGFR equations in large diverse populations and further standardization of assays is needed; especially with the Siemens Cystatin C method calibration has changed during the last five years; a downward shift in calibrator had occurred between 2006 and 2009 [32]. This has to be considered if results obtained from older lots are compared to the current study.

\section{Conclusions}

Our study in a large group of elderly shows that prevalence of CKD is very variable based on the estimating equations used and implies that $\mathrm{CysC}$ - based assessment of renal function may be more specific and helpful to identify a group of patients that may benefit from a specific intervention. More work is needed to comparatively evaluate the various estimating equations especially in elderly before we are able to assess the practical consequences of the observed differences.

\section{Abbreviations}

CKD: Chronic kidney disease; CKD-EPI: Chronic Kidney Disease Epidemiology (collaboration); CVD: Cardiovascular disease; CysC: Cystatin C; Cr: Creatinine; eGFR: Estimated glomerular filtration rate; ESRD: End stage renal disease.

\section{Competing interest}

The authors declare that they have no competing interests.

\section{Authors' contributions}

DR had conceived this study and drafted the manuscript. WK and MK organized and coordinated the laboratory measurements and helped to draft the ms. JK performed the statistical analysis. MD, TN, RP participated in the design and conduct, and coordination of the study. All authors read and approved the final manuscript.

\section{Acknowledgement}

The study was funded by a grant from the Ministry of Science, Research and Arts, state of Baden-Wuerttemberg, Germany, as part of the Geriatric Competence Center, UIm University and by funds from the Department of Internal Medicine II-Cardiology, Ulm University.

The funders had no role in study design, data collection and analysis, decision to publish, or preparation of the manuscript.

The ActiFE Ulm study group consists further of: B. Böhm, Department of Internal Medicine I - Division of Endocrinology; $\mathrm{H}$. Geiger, Department of Dermatology and Allergology; A. Lukas, Agaplesion Bethesda Clinic, Ulm; J. Stingl, Institute of Pharmacology of Natural Products \& Clinical Pharmacology; M. Riepe, Division of Gerontopsychiatry, Department of Psychiatry and Psychotherapy II; L. Rudolph, Max-Planck Group for Stem Cell Research; K. Scharffetter-Kochanek, Department of Dermatology and Allergology; Ch. Schumann, Department of Internal Medicine II Pneumology; J.M. Steinacker, Department of Sports- and Rehabilitation Medicine; A. Ludolph, C. von Arnim, Department of Neurology; G. Nagel, F. Herbolsheimer, G. Weinmayr, Institute of Epidemiology and Medical Biometry. All Institutes are located at Ulm University.

\section{Author details}

'Institute of Epidemiology and Medical Biometry, Ulm University, Ulm, Helmholtzstr 22, D-89081, Germany. ${ }^{2}$ Agaplesion Bethesda Clinic Ulm, Ulm, Germany. ${ }^{3}$ Department of Internal Medicine II-Cardiology, University of UIm Medical Centre, Ulm, Germany. 
Received: 29 November 2011 Accepted: 27 April 2012

Published: 10 May 2012

\section{References}

1. Chronic Kidney Disease Prognosis Consortium, Matsushita K, van der Velde M, Astor BC, Woodward M, et al: Association of estimated glomerular filtration rate and albuminuria with all-cause and cardiovascular mortality in general population cohorts: a collaborative meta-analysis. Lancet 2010, 375:2073-2081.

2. Zhang Q, Rothenbacher D: Prevalence of chronic kidney disease in population-based studies: systematic review. BMC Publ Health 2008, 8:117.

3. Astor BC, Matsushita K, Gansevoort RT, van der Velde M, Woodward M, et al: Lower estimated glomerular filtration rate and higher albuminuria are associated with mortality and end-stage renal disease. A collaborative meta-analysis of kidney disease population cohorts. Kidney Int 2011, 79:1331-1340

4. Nitsch D, Mann AG, Bulpitt C, Roderick PJ, Fletcher A: Impairment of kidney function and reduced quality-of-life in older people: a cross-sectional study. Age Ageing 2011, 40:381-387.

5. Levey AS, de Jong PE, Coresh J, Nahas ME, Astor BC, et al: The definition, classification and prognosis of chronic kidney disease: a KDIGO Controversies Conference report. Kidney Int 2011, 80:17-28.

6. Levey AS, Coresh J, Balk E, Kausz AT, Levin A, et al: National Kidney Foundation practice guidelines for chronic kidney disease: evaluation, classification, and stratification. Ann Intern Med 2003, 139:37-147.

7. Denkinger MD, Franke S, Rapp K, Weinmayr G, Duran-Tauleria E, et al: Accelerometer-based physical activity in a large observational cohortstudy protocol and design of the activity and function of the elderly in UIm (ActiFE Ulm) study. BMC Geriatr 2010, 10:50.

8. Klenk J, Büchele G, Rapp K, Franke S, Peter R, et al: Walking on sunshine: effect of weather conditions on physical activity in older people. $J$ Epidemiol Comm Health 2011, Feb 15. [Epub ahead of print] PubMed PMID: 21325149

9. Levey AS, Coresh J, Greene T, Stevens LA, Zhang Y, et al: Using standardized serum Creatinine values in the modification of diet in renal disease study equation for estimating glomerular filtration rate. Ann Intern Med 2006, 145:247-254.

10. Levey AS, Stevens LA, Schmid CH, Zhang YL, Castro AF 3rd, et al: A new equation to estimate glomerular filtration rate. Ann Intern Med 2009 150:604-612.

11. Inker LA, Eckfeldt J, Levey AS, Leiendecker-Foster C, Rynders G, et al: Expressing the CKD-EPI (Chronic Kidney Disease Epidemiology Collaboration) cystatin C equations for estimating GFR with standardized serum cystatin C values. Am J Kidney Dis 2011, 58:682-684.

12. Delanaye P, Pieroni L, Abshoff C, Lutteri L, Chapeklle JP, et al: Analytical study of three cystatin $C$ assays and their impact on cystatin C-based GFR-prediction equations. Clin Chim Acta 2008, 398:118-124.

13. Levey AS, Eckardt KU, Tsukamoto Y, Levin A, Coresh J, et al: Definition and classification of chronic kidney disease: a position statement from Kidney Disease: Improving Global Outcomes (KDIGO). Kidney Int 2005, 67:2089-2100.

14. Zhang QL, Koenig W, Raum E, Stegmaier C, Brenner H, et al: Epidemiology of chronic kidney disease: results from a population of older adults in Germany. Prev Med 2009, 48:122-127.

15. Stengel B, Metzger M, Froissart M, Rainfray M, Berr C, et al: Epidemiology and prognostic significance of chronic kidney disease in the elderly-the Three-City prospective cohort study. Nephrol Dial Transplant 2011, 26:3286-3295

16. Shastri $S$, Tighiouart $H$, Katz $R$, Rifkin DE, et al: Chronic kidney disease in octogenarians. Clin J Am Soc Nephrol 2011, 6:1410-1417.

17. Stevens LA, Li S, Wang C, Huang C, Becker BN, et al: Prevalence of CKD and comorbid illness in elderly patients in the United States: results from the Kidney Early Evaluation Program (KEEP). Am J Kidney Dis 2010, 55(3 Suppl 2):S23-S33.

18. Kastarinen $M$, Juutilainen $A$, Kastarinen $H$, Salomaa $V$, Karhapää $P$, et al: Risk factors for end-stage renal disease in a community-based population: 26-year follow-up of 25,821 men and women in eastern Finland. J Intern Med 2010, 267:612-620.

19. Roberts GW, Ibsen PM, Schiøler CT: Modified diet in renal disease method overestimates renal function in selected elderly patients. Age Ageing 2009, 38:698-703.
20. Delanaye P, Cavalier E, Saint-Remy A, Lutteri L, Krzesinski JM: Discrepancies between creatinine-based and cystatin C-based equations in estimating prevalence of stage 3 chronic kidney disease in an elderly population. Scand J Clin Lab Invest 2009, 69:344-349.

21. Murata K, Baumann NA, Saenger AK, Larson TS, Rule AD, et al: Relative performance of the MDRD and CKD-EPI equations for estimating glomerular filtration rate among patients with varied clinical presentations. Clin J Am Soc Nephrol 2011, 6:1963-1972.

22. van den Brand JA, van Boekel GA, Willems HL, Kiemeney LALM, der Heijer $M$, et al: Introduction of the CKD-EPI equation to estimate glomerular filtration rate in a Caucasian population. Nephrol Dial Transplant 2011, 26:3176-3181.

23. Kronborg J, Jenssen T, Njølstad I, Toft I, Eriksen BO: Metabolic risk factors associated with serum creatinine in a non-diabetic population. Eur $J$ Epidemiol 2007, 22:707-713.

24. Roderick PJ, Atkins RJ, Smeeth L, Nitsch DM, Hubbard RB, et al: Detecting chronic kidney disease in older people; what are the implications? Age Ageing 2008, 37:179-186.

25. Astor BC, Levey AS, Stevens LA, Van Lente F, Selvin E, et al: Method of glomerular filtration rate estimation affects prediction of mortality risk. J Am Soc Nephrol 2009, 20:2214-2222.

26. Peralta CA, Shlipak MG, Judd S, Cushman M, McCellan W, et al: Detection of chronic kidney disease with creatinine, cystatin $C$, and urine albumin-tocreatinine ratio and association with progression to end-stage renal disease and mortality. JAMA 2011, 305:1545-1552.

27. Zhang QL, Brenner H, Koenig W, Rothenbacher D: Prognostic value of chronic kidney disease in patients with coronary heart disease: role of estimating equations. Atherosclerosis 2010, 211:342-347.

28. Roos JF, Doust J, Tett SE, Kirkpatrick CM, et al: Diagnostic accuracy of cystatin $C$ compared to serum creatinine for the estimation of renal dysfunction in adults and children - A meta-analysis. Clin Biochem 2007, 40:383-391.

29. Glassock RJ, Winearls C: Screening for CKD with eGFR: doubts and dangers. Clin J Am Soc Nephrol 2008, 3:1563-1568.

30. Glassock RJ, Winearls C: An epidemic of chronic kidney disease: fact or fiction? Nephrol Dial Transplant 2008, 23:1117-1121.

31. Lamb EJ, O'Riordian SE, Delaney MP: Kidney function in older people: pathology, assessment and management. Clin Chim Acta 2003, 334:25-40.

32. Larsson A, Hansson LO, Flodin M, Katz R, Shlipak MG: Calibration of the Siemens cystatin $C$ immunoassay has changed over time. Clin Chem 2011, 57:777-778.

\section{doi:10.1186/1471-2458-12-343}

Cite this article as: Rothenbacher et al:: Prevalence and determinants of chronic kidney disease in community-dwelling elderly by various estimating equations. BMC Public Health 2012 12:343.

\section{Submit your next manuscript to BioMed Central and take full advantage of:}

- Convenient online submission

- Thorough peer review

- No space constraints or color figure charges

- Immediate publication on acceptance

- Inclusion in PubMed, CAS, Scopus and Google Scholar

- Research which is freely available for redistribution 